\title{
The red seaweed Plocamium brasiliense shows anti-snake venom toxic effects
}

\author{
Geisiane Alves da Silva', Thaisa Francielle Souza Domingos' ${ }^{1}$, Rainiomar Raimundo Fonseca ${ }^{2}$ \\ Eladio Flores Sanchez ${ }^{3}$, Valéria Laneuville Teixeira ${ }^{4}$ and André Lopes Fuly ${ }^{1 *}$
}

\begin{abstract}
Background: Snakebite is considered a neglected tropical disease by the World Health Organization. In Brazil, about $70 \%$ of the envenomation cases are caused by Bothrops snakes. Its venom may provoke hemorrhage, pain, necrosis, hemolysis, renal or cardiac failure and even death in victims. Since commercial antivenom does not efficiently neutralize the local toxic effects of venoms, natural products have been tested in order to provide alternative or complementary treatment to serum therapy. Therefore, the present study aimed to evaluate the ability of the seaweed Plocamium brasiliense and its active derivatives to neutralize hemorrhagic, edematogenic, hemolytic, coagulant and proteolytic activities of $B$. jararaca venom.
\end{abstract}

Methods: Specimens of P. brasiliense were collected in Rio de Janeiro state, Brazil, dried and submitted to oil extraction using four solvents of increasing polarities, n-hexane (HEX), dichloromethane (DCM), ethyl acetate (ETA) and hydroalcoholic solution (HYD). The solvents were evaporated, yielding HEX, DCM, ETA and HYD extracts. Further, all extracts were dissolved in dimethylsulfoxide. In addition, two monoterpenes (8-bromo-3,4,7-trichloro-3,7dimethyl-1E, 5E-octadiene and 1,8-dibromo-3,4,7-trichloro-3,7-dimethyl-1E, 5E-octadiene) and a cholesterol fraction were isolated from the extract of $P$. brasiliense prepared in hexane. Algal samples were incubated for 30 minutes with B. jararaca venom, and then tested for lethality; hemorrhagic, edematogenic, hemolytic, coagulant and proteolytic effects.

Results: Most of the algal extracts inhibited the toxic effects with different potencies. The DCM extract was the most effective, since it inhibited all types of toxic activity. On the other hand, the HYD extract failed to inhibit any effect. Moreover, the isolated products inhibited proteolysis and protected mice from hemorrhage in 30\% of the cases, whereas 8-bromo-3,4,7-trichloro-3,7-dimethyl-1E, 5E-octadiene inhibited 100\% and 20\% of the hemorrhagic and proteolytic activities, respectively. None of the algal products were toxic to mice.

Conclusion: Seaweeds may be a promising source of inhibitors against toxic effects caused by B. jararaca envenomation, which may contribute to antivenom treatment.

Keywords: Bothrops jararaca, Snake venom, Plocamium brasiliense, Seaweed, Antivenom, Bioprospecting

\section{Background}

Snakebites comprise a serious health problem in numerous parts of the world, due to their seriousness, sequelae and high fatality rates. According to the World Health Organization [1], up to five million people are bitten by snakes every year, and around 2 million of these people die, whereas 400,000 cases end in amputations and other

\footnotetext{
*Correspondence: andfuly@vm.uff.br

'Department of Molecular and Cellular Biology, Institute of Biology, Federal

Fluminense University (UFF), Niterói, Rio de Janeiro State, Brazil

Full list of author information is available at the end of the article
}

severe health consequences, such as infection, tetanus, scarring, contractures, and psychological sequelae $[1,2]$. According to Kasturiratne et al. [3], 420,000 to 1,841,000 snakebites occur per year worldwide with 20,000 to 94,000 deaths. However, research indicates that the burden of envenomation by snakes may be even heavier.

In Brazil, snakes of the Bothrops genus are involved in most cases of human envenomation, about 70\%, particularly the species $B$. jararaca $[4,5]$. Bothrops venoms, which have been extensively studied, are composed of a complex mixture of proteins, peptides and other organic 
and inorganic molecules that induce local (pain, edema, necrosis, inflammation, hemorrhage) and systemic (coagulation disturbances, renal and cardiac failure) effects in victims [6-13]. B. jararaca is found in southern Brazil, Paraguay, and northern Argentina. Envenomation by this species has a similar profile to that observed in other Bothrops species including shock, tissue necrosis, intravascular coagulation, local and systemic hemorrhage and edema.

The recommended treatment for envenomation by this species is polyvalent Bothrops antivenom, which is produced by horse hyperimmunization [14-16]. In spite of inhibiting systemic toxic effects, antivenom has a few disadvantages including ineffectiveness against local effects and side effects [17-19]. In addition, the variability in venom composition of different Bothrops species may affect the antivenom efficacy. Therefore, alternative strategies and treatments have been extensively investigated $[20,21]$. In most developing countries, about $80 \%$ of snakebite victims seek help first from traditional practitioners that use plant extracts. Appropriate medical care with antivenom therapy is usually their second option [21]. Thus, natural products are good candidates for alternative treatments. The seas provide an amazing source of molecules when compared to the terrestrial environment; however, little is known about their biological or pharmacological functions. Marine organisms produce molecules derived from primary and secondary metabolism with biological and pharmacological effects, such as antiviral, anticancer, anticoagulant and antiplatelet activities [22-26]. Previously, antivenom activity has been described in marine algae and sponges, which showed that both organisms can inhibit some toxic effects of Lachesis muta and B. jararaca venoms [27,28].

In the present study, the red seaweed Plocamium brasiliense (Greville) M. Howe and W.R. Taylor has been investigated. The genus Plocamium Lamouroux (Plocamiaceae, Rhodophiceae) contains more than 40 species that are widely distributed over the oceans. $P$. brasiliense is abundant off the east-southeast coast of Brazil [29]. These marine algae produce acyclic and cyclic halogenated monoterpenes, of which more than $100 \mathrm{~mol}-$ ecules have been isolated [29,30]. Such molecules have shown biological activities including antimicrobial, antifungal, ichthyotoxic, cytotoxic and insecticidal properties as well as antiviral activity against herpes virus [31,32]. Moreover, $P$. brasiliense may be used as herbicide or even as food [33]. It has been shown that three products isolated from $P$. brasiliense inhibited some toxic in vitro and in vivo activities of $B$. jararaca venom: monoterpene 1 (8-bromo-3,4,7-trichloro-3,7-dimethyl-1E, 5E-octadiene), monoterpene 2 (1,8-dibromo-3,4,7-trichloro-3,7-dimethyl1E, 5E-octadiene) and a cholesterol [30,32,34]. Their chemical structures are shown in Figure 1.
The aim of the present study was to evaluate the inhibitory potential of extracts of $P$. brasiliense and of their isolated products (the two monoterpenes and cholesterol) against some in vitro (proteolysis, coagulation and hemolysis) and in vivo (hemorrhage, lethality and edema) toxic effects induced by $B$. jararaca snake venom.

\section{Methods}

Algal material

Specimens of $P$. brasiliense were collected by snorkeling in October 2010, at Enseada do Forno beach, in the city of Armação de Búzios, located in the north of Rio de Janeiro state, Brazil $\left(22^{\circ} 45^{\prime} \mathrm{S}, 41^{\circ} 52^{\prime} \mathrm{W}\right)$. They were washed with local seawater and separated from sediments, epiphytes and other associated organisms. The algae were dried for twenty days and their extracts were obtained by using appropriate solvent. Voucher specimens were deposited in the Herbarium of the Rio de Janeiro State University (HRJ 10331-32). The Brazilian algal collection license (VLT) number is 10594. (IBAMA/ SISBIO).

\section{Preparation of crude extracts and fractions}

$P$. brasiliense was collected and dried at room temperature (average of $28^{\circ} \mathrm{C}$ ). Then, the algal crude extract was ground in an industrial blender and placed into a plastic tray, yielding $5.16 \mathrm{~g}$ of powdered algae. P. brasiliense oil extraction was performed using the solvents hexane, dichloromethane, ethyl acetate and ethanol/water. Afterwards, all solvents were evaporated off under reduced pressure, yielding a crude residue. An aliquot of each extract was weighed, aliquoted and frozen at $-20^{\circ} \mathrm{C}$, and finally, the extracts were dissolved in dimethylsulfoxide (DMSO, 30\% v/v) to perform the biological assays.

The extracts were obtained according to Fonseca et al. [31] and yielded the following values: $\mathrm{n}$-hexane, $500 \mathrm{mg}$; dichloromethane, $196 \mathrm{mg}$; ethyl acetate, $42 \mathrm{mg}$; and ethanol/water, $250 \mathrm{mg}$. The extract prepared in n-hexane (500 mg) was subjected to silica gel 70-230 mesh column chromatography $(4 \times 70 \mathrm{~cm})$ eluted with $\mathrm{n}$-hexane, $\mathrm{CH}_{2} \mathrm{Cl}_{2}$, EtOAc and $\mathrm{MeOH}$ in sequence, resulting in 97 fractions of $10 \mathrm{~mL}$ each (F1 to F97) and 55 fractions of $20 \mathrm{~mL}$ each (F98 to F153). The fraction F17 (18 mg) eluted with n-hexane/ $\mathrm{CH}_{2} \mathrm{Cl}_{2}$ (9.7:0.3) and the fraction F76 (16 mg) eluted with $n$-hexane/ $\mathrm{CH}_{2} \mathrm{Cl}_{2}$ (5:5) contained the pure halogenated monoterpenes 1 and 2, respectively. The fractions F112 to F118 eluted with n-hexane/CH2Cl2 (3.5:6.5) and F119-F125 eluted with n-hexane $/ \mathrm{CH}_{2} \mathrm{Cl}_{2}$ (3:7) contained the pure cholesterol (42 $\mathrm{mg}$ ). These fractions were also obtained according to the method by Fonseca et al. [31], and were analyzed according to Vasconcelos et al. [30] by HRGC/MS on a HP 5890 series GC system, coupled to a HP 5973 mass selective detector in the EI mode $(70 \mathrm{eV})$ equipped with 
<smiles>C[C@@H](Cl)/C=C\C=C/C(=O)[C@H](Cl)Br</smiles>

(1)<smiles>C[C@@H](Cl)/C(=C\C=C\Br)C(Cl)Cl</smiles>

(2)<smiles>CC(C)CCC[C@H](C)[C@H]1CC[C@H]2C3CC=C4C[C@@H](O)CC[C@]4(C)C3CC[C@@]21C</smiles>

(3)

Figure 1 Chemical structure of (1) monoterpene 1 (8-bromo-3,4,7-trichloro-3,7-dimethyl-1E,5E-octadiene), (2) monoterpene 2 (1,8-dibromo-3,4,7-trichloro-3,7-dimethyl-1E,5E-octadiene) and of the (3) cholesterol fraction.

a HP-1 MS capillary column $(30 \mathrm{~m} \times 0.25 \mathrm{~mm}$, film thickness $0.25 \mu \mathrm{m})$, and dissolved in DMSO (30\%, v/v) as well.

\section{Venom and animals}

B. jararaca venom was kindly supplied by the Ezequiel Dias Foundation (FUNED), Belo Horizonte, Minas Gerais state, Brazil, vacuum dried and stored at $-20^{\circ} \mathrm{C}$ until use. Male Balb/c mice (Mus musculus species) weighting 18-20 g were obtained from the Center of Laboratory Animals (NAL) of the Federal Fluminense University (UFF). They were housed under controlled conditions of temperature $\left(24 \pm 1^{\circ} \mathrm{C}\right)$ and light. All the experiments performed were approved by the UFF Institutional Committee for Ethics in Animal Experimentation (CEUA: 200/10) and were in accordance with the guidelines of the Brazilian Committee for Animal Experimentation (COBEA).

\section{Antihemolytic activity}

The degree of hemolysis of B. jararaca venom was determined by the indirect hemolytic test using human erythrocytes and hen's egg yolk emulsion as substrates [35]. The lowest amount of B. jararaca venom that produced $100 \%$ hemolysis was called the minimum indirect hemolytic dose (MIHD). Inhibitory experiments were performed by incubating algal extracts with one MIHD for 30 minutes at room temperature, and then, hemolytic activity was evaluated. Positive controls were performed by incubating venom with DMSO (5\% v/v) or saline solution, instead of extracts. DMSO (5\% v/v) or extracts alone were used as negative controls.

\section{Anticoagulant activity}

The coagulant activity of $B$. jararaca venom was monitored using a digital Amelung coagulometer, model KC4A (Labcon, Germany). Different concentrations of $B$. jararaca venom were mixed with diluted citrated plasma (1:1 in saline) donated from healthy volunteers collected at a local public blood bank (University Hospital Antônio Pedro of UFF). The amount of venom $(\mu \mathrm{g} / \mathrm{mL})$ that clotted plasma in 60 seconds was called the minimum coagulant dose (MCD). To evaluate the inhibitory effect, algal extracts were incubated for 30 minutes at room temperature with one $\mathrm{MCD}$, and then, the mixture was added to plasma and coagulation time was recorded. Positive controls were performed in parallel by incubating venom with DMSO $(1 \% \mathrm{v} / \mathrm{v})$ or saline solution. DMSO $(1 \% \mathrm{v} / \mathrm{v})$ or extracts alone were used as negative controls.

\section{Antiproteolytic activity}

Proteolytic activity of $B$. jararaca venom was determined using azocasein as substrate $(0.2 \% \mathrm{w} / \mathrm{v}$, in $20 \mathrm{mM}$ Tris- $\mathrm{HCl}$, $8 \mathrm{mM} \mathrm{CaCl}_{2}, \mathrm{pH} \mathrm{8.8)} \mathrm{[36]} \mathrm{-} \mathrm{with} \mathrm{minor} \mathrm{modifications.} \mathrm{An}$ 
effective concentration (EC) was defined as the amount of $B$. jararaca venom $(\mu \mathrm{g} / \mathrm{mL})$ able to produce a variation of about 0.2 OD units at A $420 \mathrm{~nm}$ (spectrophotometer Hitachi U-5100). The inhibitory effect of algal extracts was performed by incubating them with two EC of B. jararaca venom for 30 minutes at room temperature and then, proteolysis was measured. Similarly, control experiments were conducted by mixing venom with DMSO $(5 \% \mathrm{v} / \mathrm{v})$ or saline solution and, further proteolysis was performed. DMSO $(5 \% \mathrm{v} / \mathrm{v})$ or extracts were used as negative controls.

\section{Antihemorrhagic activity}

Hemorrhagic lesions produced by $B$. jararaca venom were quantified using a procedure described by Kondo et al. [37] with modifications. Briefly, samples $(100 \mu \mathrm{L})$ were injected intradermally (i.d.) into abdominal skin of mice. Two hours later, the animals were euthanized, abdominal skin was removed, stretched and inspected for visual changes in the inner surface of subcutaneous layers in order to find hemorrhagic spots. Hemorrhage was classified into minimum hemorrhagic dose (MHD), defined as the amount of $B$. jararaca venom $(\mu \mathrm{g} / \mathrm{g})$ able to produce a hemorrhagic halo of $10 \mathrm{~mm}$ [38]. The inhibitory effect of algal extracts was investigated by incubating them with two MHD of B. jararaca venom for 30 minutes at room temperature and then, the mixture $(100 \mu \mathrm{L})$ was injected i.d. into mice and hemorrhage was observed. Hemorrhagic activity was expressed as the mean diameter (in millimeters) of the hemorrhagic halo induced by $B$. jararaca venom in the absence and presence of algae. Negative controls were performed by injecting only DMSO $(5 \% \mathrm{v} / \mathrm{v})$, extracts or saline solution.

\section{Antiedematogenic activity}

Edema-inducing activity of B. jararaca venom was determined according to Yamakawa et al. [39]. Groups of five mice received $50 \mu \mathrm{L}$ of $B$. jararaca venom subcutaneously (s.c.) in the right paw, while the left paw received $50 \mu \mathrm{L}$ of saline solution or DMSO. One hour after injection, edema was evaluated as the percentage increase in weight of the right paw compared to the left one. Antiedematogenic activity was performed by incubating algal extracts with $B$. jararaca venom for 30 minutes at room temperature, and then the mixture was injected s.c. into mice. Control experiments were performed by mixing $B$. jararaca venom with DMSO (5\% v/v) or saline solution. For negative controls, DMSO $(5 \% \mathrm{v} / \mathrm{v})$ or extracts were injected.

\section{Anti-lethal activity}

Groups of six mice received $(100 \mu \mathrm{L})$ intraperitoneally (i.p.) B. jararaca venom $(20 \mu \mathrm{g} / \mathrm{g})$ and were observed for 48 hours. The anti-lethal assay was performed by incubating B. jararaca $(20 \mu \mathrm{g} / \mathrm{g})$ with algal extracts $(80 \mu \mathrm{g} / \mathrm{g})$ for 30 minutes at room temperature and the mixture was injected i.p. into mice. Positive control groups received $B$. jararaca mixed with saline solution or DMSO, and negative controls received algal extracts instead of venom.

\section{Statistical analysis}

Results are presented as means \pm S.E.M. The statistical significance of differences between tests was evaluated by Student's unpaired $t$-test. p values of $<0.05$ were considered statistically significant.

\section{Results}

Effect of $P$. brasiliense extracts on $B$. jararaca venom-induced coagulation

B. jararaca venom $(20 \mu \mathrm{g} / \mathrm{mL})$ clots plasma usually in 70 seconds. Therefore, this venom concentration was mixed with $P$. brasiliense extracts $(100 \mu \mathrm{g} / \mathrm{mL})$ in order to evaluate the effects on coagulation (Figure 2). As shown in Figure 2, the algal extracts inhibited the coagulant activity of $B$. jararaca venom in different degrees. The extracts prepared in dichloromethane (Figure 2, group II)

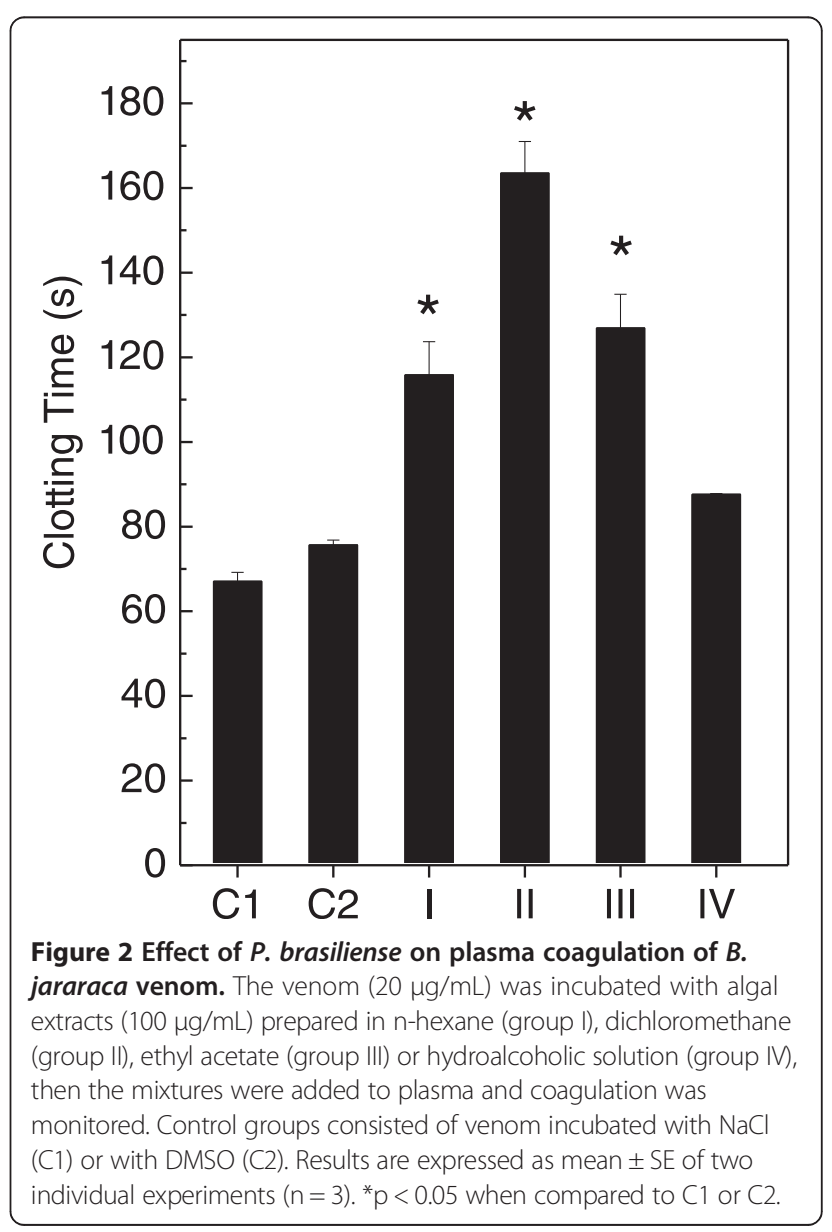


and hydroalcoholic solution (Figure 2, group IV) inhibited more and less efficiently, respectively. When tested alone, the extracts did not induce coagulation.

\section{Effect of $P$. brasiliense extracts on $B$. jararaca venom-induced proteolysis}

P. brasiliense extracts (10 and $100 \mu \mathrm{g} / \mathrm{mL})$ inhibited the proteolytic activity of $10 \mu \mathrm{g} / \mathrm{mL}$ of $B$. jararaca venom (Figure 3). Regardless of the concentration, the dichloromethane extract had the highest inhibitory activity (Figure 3, group II), while the hydroalcoholic solution did not inhibit at all (Figure 3, group IV). The other two extracts (n-hexane, group I, and ethyl acetate, group III, at $100 \mu \mathrm{g} / \mathrm{mL}$ ) inhibited proteolysis by $57 \%$ and $84 \%$, respectively. In addition, the monoterpenes 1 and 2 inhibited by $20 \%$ and $38 \%$, respectively, while the cholesterol inhibited proteolysis induced by $B$. jararaca venom by $32 \%$ (Table 1 ). The extracts alone were not able to hydrolyze azocasein.

\section{Effect of $P$. brasiliense extracts on $B$. jararaca} venom-induced hemolysis

The extracts were not able to lyse erythrocytes. However, the hemolysis caused by $B$. jararaca venom $(30 \mu \mathrm{g} / \mathrm{mL})$

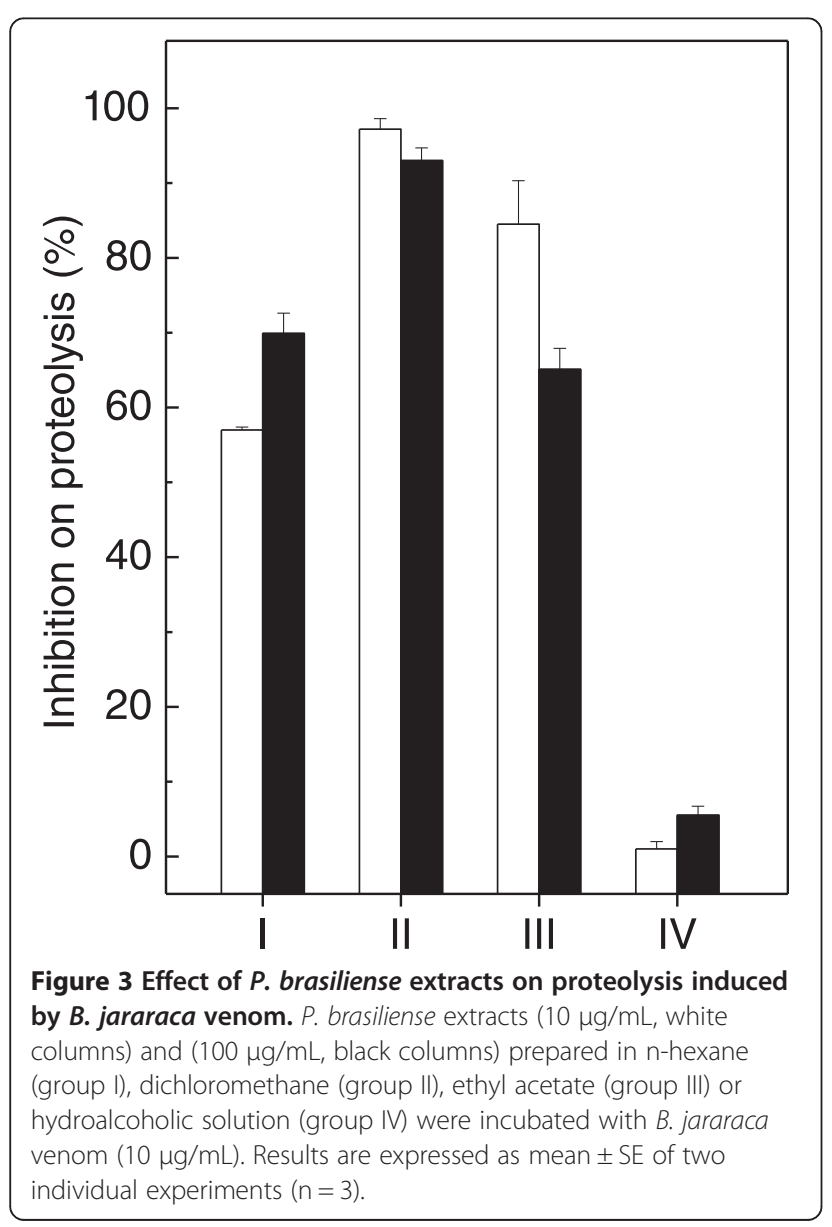

Table 1 Antiproteolytic and antihemorrhagic effects of $P$. brasiliense products

\begin{tabular}{lll}
\hline Sample & Inhibition (\%) \\
\cline { 2 - 3 } & Proteolysis & Hemorrhage \\
\hline B. jararaca + monoterpene 1 & $20 \pm 4.5$ & 100 \\
\hline B. jararaca + monoterpene 2 & $37 \pm 2.1$ & $32 \pm 11$ \\
\hline B. jararaca + cholesterol & $33 \pm 2.5$ & $28 \pm 6$ \\
\hline
\end{tabular}

Monoterpene 1: 8-bromo-3,4,7-trichloro-3,7-dimethyl-1E,5E-octadiene; monoterpene 2: 1,8-dibromo-3,4,7-trichloro-3,7-dimethyl-1E,5E-octadiene.

was inhibited significantly by all $P$. brasiliense extracts (90 and $180 \mu \mathrm{g} / \mathrm{mL}$ ), except for the hydroalcoholic solution (Figure 4). The extract prepared in dichloromethane inhibited hemolysis by $88 \%$ and $98 \%$, at $1: 3$ and $1: 6$ venom:algae ratios $(\mathrm{w} / \mathrm{w})$, respectively (Figure 4 , group II). At both venom:algae ratios, the ethyl acetate extract inhibited proteolysis by $25 \%$ (Figure 4 , group III).

Effect of $P$. brasiliense extracts on $B$. jararaca venom-induced hemorrhage, edema and lethality P. brasiliense extracts prepared in different solvents and their isolated products inhibited hemorrhage and edematogenic

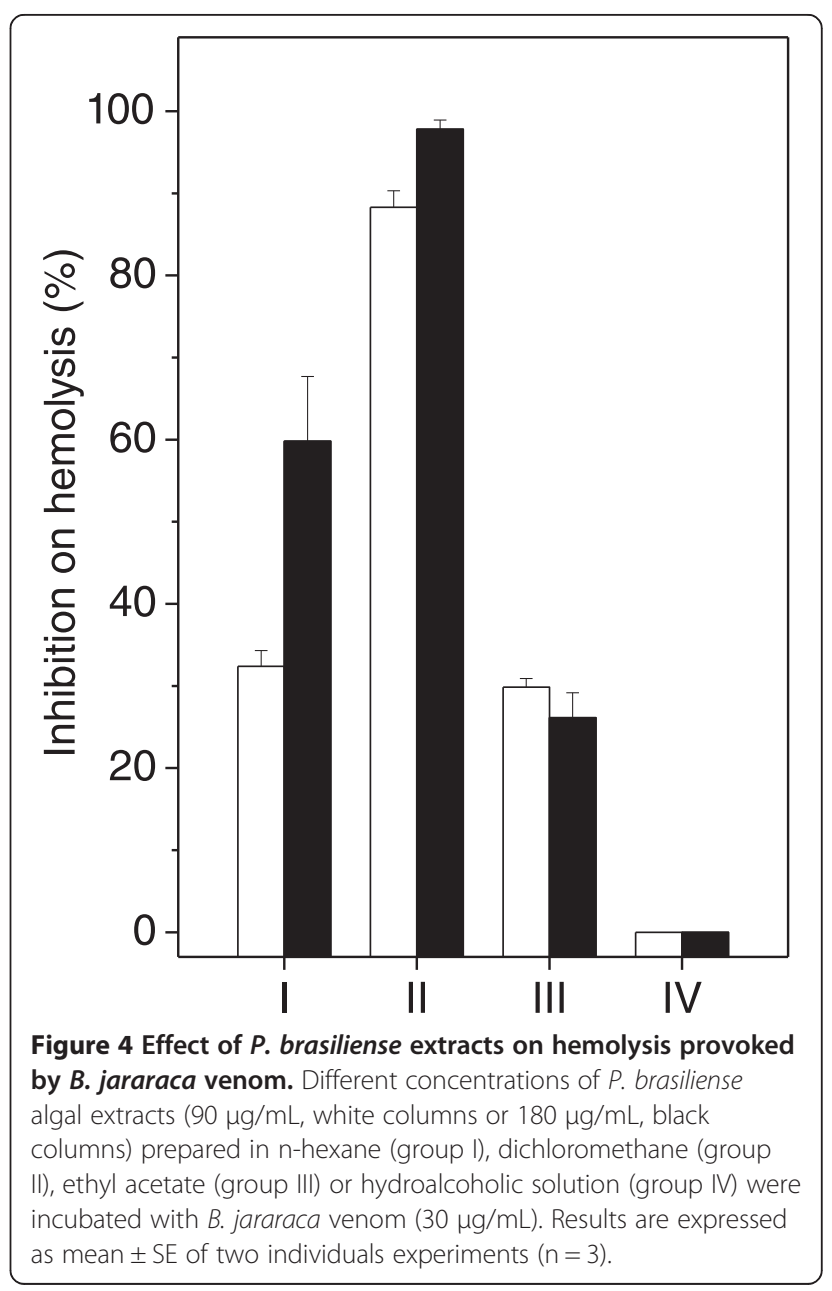


activities in vivo of $B$. jararaca venom (Figure 5 ). The extracts $(15 \mu \mathrm{g} / \mathrm{mL})$ prepared in $\mathrm{n}$-hexane (group I), dichloromethane (group II) and ethyl acetate (group III) fully inhibited $B$. jararaca venom-induced hemorrhage, except for the one prepared in hydroalcoholic solution (group IV) (Figure 5A). The isolated products from $P$. brasiliense $(15 \mu \mathrm{g} / \mathrm{mL})$ monoterpene 2 and cholesterol inhibited hemorrhagic activity of B. jararaca venom by $30 \%$, while the monoterpene 1 inhibited 100\% hemorrhage (Table 1).

Edema provoked by $B$. jararaca venom was also inhibited by the extracts of $P$. brasiliense (Figure 5B). Those prepared in dichloromethane (Figure 5B, group II) and ethyl acetate (Figure 5B, group III) inhibited edema by $22 \%$, while extracts in hexane and hydroalcoholic solution inhibited by $15 \%$ and $2 \%$, respectively (Figure $5 B$ ).

Mice injected with $B$. jararaca venom $(20 \mu \mathrm{g} / \mathrm{g})$ died in about 10 hours. Incubation of venom with derived products $(80 \mu \mathrm{g} / \mathrm{g})$ did not protect the animals against the lethal effects of $B$. jararaca venom (data not shown). When algal extracts alone, products or vehicle (DMSO or saline) were injected into animals, no hemorrhage, edema or death was seen. Therefore, extracts and derived products were not toxic to mice.

\section{Discussion}

Envenomation resulting from snakebites is a particularly important public health problem in rural areas of tropical and subtropical countries [1,2]. In Brazil, according to the registers of the Brazilian Ministry of Health, about 30,000 victims are envenomated per year with hundreds of deaths $[1,4,40,41]$. However, these numbers are not accurate since snakebites often occur in areas where there is no health unit or hospital to record the case. Snakebite is a neglected tropical disease; hence, little attention has been given by the pharmaceutical industry, governments and academia to improve antivenom therapy.

In Brazil, antivenom is the only treatment available against snakebites, but it has some limitations and disadvantages. Therefore, alternative treatments, including natural products, have been investigated to complement or to replace antivenom therapy. Plant extracts have been used in folk medicine to treat or to ameliorate several conditions, including snakebites, and many scientific reports have proven their efficacy [21,42]. In contrast, the research on marine algae as inhibitors of toxic effects of snake venoms is limited. Previous results from our group have shown the inhibitory activity of plants, marine sponges and seaweed against snake venoms, but little is known about antivenom properties of algae such as $P$. brasiliense [28,43-45]. An initial study was conducted by Claudino et al. [34] analyzing the inhibitory action of $P$. brasiliense extract against the toxic effects of L. muta snake venom. Apart from antivenom activities, some biological and pharmacological properties have been found in these algae and their derived products, such as defense against marine herbivores and antiviral activity [31,32].

In the present work, we showed that $P$. brasiliense crude extracts - prepared in n-hexane (HEX), dichloromethane (DCM), ethyl acetate (ETA) and hydroalcoholic solution (HYD) - and three isolated products from HEX fractions (two halogenated monoterpenes and a cholesterol) inhibited in vivo and in vitro activities induced by $B$. jararaca venom. All the solvents employed are of increasing polarities, therefore they able to extract molecules
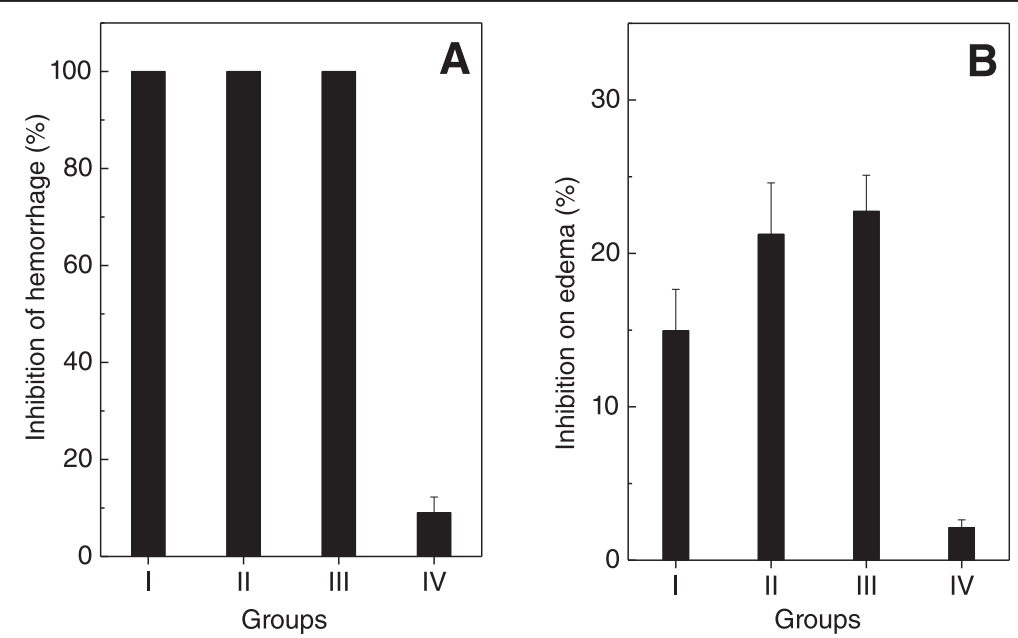

Figure 5 Effect of $\boldsymbol{P}$. brasiliense extracts on hemorrhage and edema induced by $\boldsymbol{B}$. jararaca venom. The algal extracts $(35 \mu \mathrm{g} / \mathrm{g}) \mathrm{prepared}$ in n-hexane (group I), dichloromethane (group II), ethyl acetate (group III) and hydroalcoholic solution (group IV) were incubated with B. jararaca venom $(25 \mu \mathrm{g} / \mathrm{g}$ ). Then, mixtures were injected into mice and hemorrhagic (Panel A) or edematogenic (Panel B) activities were analyzed, as described in methods. Results are expressed as mean \pm SE of two individuals experiments $(n=3)$. 
derived from the secondary metabolism. The medium polarity solvent DCM inhibited most activities of $B$. jararaca venom whereas HYD, with the highest polarity solvent, recorded no inhibitory activity.

$B$. jararaca venom is rich in serine proteinases, metalloproteinases, phospholipases and phosphoesterases that affect the nervous system, blood coagulation, muscle tissue, red blood cells and other organs [46]. Furthermore, these enzymes are directly involved in local effects that are responsible for amputations and deformities as well as in systemic symptoms in victims [47]. B. jararaca venom induces coagulation, and thrombin-like enzymes participate in such action, leading plasma to clot and venom-induced consumptive coagulopathy. DCM, in particular, inhibited coagulation induced by $B$. jararaca venom, preventing fibrin production. However, it is unknown whether DCM extract interacts with components of the intrinsic and/or extrinsic pathways of the coagulation system. Moreover, DCM, HEX and ETA prevented proteolytic activity of $B$. jararaca venom, so that they may be interacting with proteases in such venom. In contrast, the extract prepared in HYD failed to inhibit proteolysis and coagulation provoked by $B$. jararaca venom. The two monoterpenes and the cholesterol fraction inhibited proteolysis of $B$. jararaca venom.

The crude extracts of $P$. brasiliense and the isolated products protected mice from hemorrhage and edema, except for HYD extract. The monoterpene 2 and the cholesterol derivatives inhibited around 30\% of hemorrhage, whereas the monoterpene 1 fully inhibited it. Hemorrhagic activity of venoms is due to the action of metalloproteases and phospholipases $\mathrm{A}_{2}\left(\mathrm{PLA}_{2}\right)$. Several symptoms of envenomation by snakes such as coagulation and hemorrhage are associated with such enzymes, and they are one of the major groups of enzymes that cause the deleterious effects of venoms in victims $[48,49]$. The antivenom properties of extracts and derived products may be related to an inhibitory action upon such key enzymes. In the literature, many hypotheses have been proposed as mechanisms of inhibitory action of plants as well as any other natural sources, as protein precipitation, enzyme inactivation, metal chelation and antioxidant effect. However, the mechanism by which neutralization occurs is unknown [50].

In addition to hemorrhage, edematogenic activity should be considered in envenomation. It may be caused by the action of $\mathrm{PLA}_{2} \mathrm{~S}$ that are poorly inhibited by commercial antivenoms [51]. $\mathrm{PLA}_{2} \mathrm{~S}$ are calcium-dependent enzymes from venoms that induce edema, myotoxicity and lysis of the red blood cells, and these effects may contribute to morbidities or disabilities frequently observed in B. jararaca envenomation [52]. The DCM (98\%) and HEX (60\%) extracts effectively inhibited hemolysis. In the literature, researchers have made efforts in order to neutralize PLA 2 enzymes, providing protection against snakebite symptoms. In this regard, edema induced by $B$. jararaca venom was inhibited by the extract of $P$. brasiliense as well in the present study. $\mathrm{PLA}_{2} \mathrm{~S}$ also participate in the formation of lysolecithin (also called lysophosphatidylcholine), which is formed by the hydrolysis of phospholipids. Moreover, the toxic action of lysolecithin formed by the action of $\mathrm{PLA}_{2} \mathrm{~S}$ from other sources of venoms has also been investigated. A PLA P $_{2}$ isolated from $L$. muta venom modulates natural killer activity by the protein kinase $C$ pathway [53]. $B$. jararaca venom contains several isoenzymes of PLA, serine proteases and metalloproteases that cause edema, coagulation and hemorrhage, respectively. However, any inhibitory effect cannot be attributed just to a specific group of enzymes since DCM and HEX extracts and monoterpene 1 fully inhibited all these toxic activities. It is worth noting that the less polar fractions, DCM and HEX, inhibited the toxic activities of $B$. jararaca venom more effectively, while the more polar, HYD did not inhibit such activities.

These products derived from $P$. brasiliense could be useful for treating the local effects induced by $B$. jararaca venom, since antivenom is not fully effective in preventing them, leading snakebite victims to amputations. To produce a single molecule or extract able to inhibit all the toxic activities of snake venom is a challenge as is developing an effective treatment, since there are ontogenetic variations in snake venom of $B$. jararaca [54]. $B$. jararaca venom, or any other snake venom, has different domain composition, glycosylation patterns and tertiary or quaternary structure, thus displaying different toxicity profiles and different or variable susceptibilities to inhibitors [55]. This fact greatly increases the difficulty in obtaining an entirely effective molecule able to fully neutralize the toxic effects and symptoms of envenomation by snakes. However, natural products such as the algal extracts described in the present paper provide hope for the future.

Marine seaweed produce biologically active molecules that have several pharmacological effects. In the present study, P. brasiliense extracts and three isolated products neutralized the main harmful effects of $B$. jararaca venom, both systemic (hemolysis, coagulation and hemorrhage) and local (edema and hemorrhage) symptoms observed in snakebite victims. However, venom-induced lethality was not prevented by algal extracts. In our opinion, the ineffectiveness concerning lethal outcomes should not be considered a discouraging result, since antivenom therapy efficiently neutralizes it [51]. In conclusion, these extracts have potential to be used to complement treatment of victims of $B$. jararaca envenomation. The present research aims to stimulate the development of new antivenom drugs based on further studies on algal and other natural products. 


\section{Conclusion}

The crude extracts of $P$. brasiliense and their isolated products inhibited in vivo and in vitro some harmful effects induced by the venom of $B$. jararaca. Therefore, these marine algae have biotechnological potential to lead to the development of alternative or complementary therapy for snake envenomation caused by $B$. jararaca.

\section{Ethics committee approval}

The present study was approved by UFF Institutional Committee for Ethics in Animal Experimentation (CEUA, 200/10). All experiments were in accordance with the guidelines of the Brazilian Committee for Animal Experimentation (COBEA).

\section{Competing interests}

The authors declare that they have no competing interests.

\section{Authors' contributions}

ALF, GAS and TFSD performed experiments and helped in article writting RRF and VLT performed the collection of marine algae, oil extraction and isolation of algal products. ALF, VLT, EFS participated in the analysis of the results and writting. ALF is the lead researcher of this study. All authors read and approved the final manuscript.

\section{Acknowledgments}

This work was supported by the International Foundation for Science (F/4571-1) and by the Brazilian funding agencies: the National Council for Scientific and Technological Development (CPNq), State of Rio de Janeiro Research Foundation (FAPERJ), Coordination for the Improvement of Higher Education Personnel (CAPES) and UFF/PROPPi. We would like to thank M. D. Olga Maria Diniz Pereira (UFF) for providing the blood bags and Dr. Norman Ratcliffe, from the Swansea University, United Kingdom, for kindly revising the manuscript.

\section{Author details \\ 'Department of Molecular and Cellular Biology, Institute of Biology, Federal Fluminense University (UFF), Niterói, Rio de Janeiro State, Brazil. ${ }^{2}$ Department of Organic Chemistry, Institute of Chemistry, Federal Fluminense University (UFF), Niterói, Rio de Janeiro State, Brazil. 'aboratory of Biochemistry of Proteins from Animal Venoms, Research and Development Center, Ezequiel Dias Foundation, Belo Horizonte, Minas Gerais State, Brazil. ${ }^{4}$ Department of Marine Biology, Institute of Biology, Federal Fluminense University (UFF), Niterói, Rio de Janeiro State, Brazil.}

\section{Received: 1 September 2014 Accepted: 27 January 2015}

Published online: 10 February 2015

\section{References}

1. World Health Organization. WHO guidelines for the production control and regulation of snake antivenom immunoglobulins. Geneva, Switzerland: World Health Organization; 2010.

2. Chippaux JP. Snake-bites: appraisal of the global situation. Bull World Health Organ. 1998;76(5):515-24.

3. Kasturiratne A, Wickremasinghe AR, de Silva N, Gunawardena NK, Pathmeswaran A, Premaratna R, et al. The global burden of snakebite: a literature analysis and modelling based on regional estimates of envenoming and deaths. Plos Med. 2008;5(11):1591-604.

4. Bochner R, Struchiner CJ. Epidemiologia dos acidentes ofídicos nos últimos 100 anos no Brasil: uma revisão. Cad Saude Publica. 2003;19(1):7-16.

5. Sistema de Informação de Agravos de Notificação - Sinan. Ministério da Saúde do Brasil, Brasília. 2010. http://dtr2004.saude.gov.br/sinanweb/index. php. Accessed 25 Jan 2015.

6. Alape-Girón A, Sanz L, Escolano J, Flores-Díaz M, Madrigal M, Sasa M, et al. Snake venomics of the lancehead pitviper Bothrops asper: geographic, individual, and ontogenetic variations. J Proteome Res. 2008;7(8):3556-71.
7. Calvete JJ, Sanz L, Pérez A, Borges A, Vargas AM, Lomonte B, et al. Snake population venomics and antivenomics of Bothrops atrox: paedomorphism along its transamazonian dispersal and implications of geographic venom variability on snakebite management. J Proteomics. 2011;74(4):510-27.

8. Gutiérrez JM, Sanz L, Escolano J, Fernandez J, Lomonte B, Angulo Y, et al. Snake venomics of the Lesser Antillean pit vipers Bothrops caribbaeus and Bothrops lanceolatus: correlation with toxicological activities and immunoreactivity of a heterologous antivenom. J Proteome Res. 2008;7(10):4396-408.

9. Sousa LF, Nicolau CA, Peixoto PS, Bernardoni JL, Oliveira SS, Portes-Junior $J A$, et al. Comparison of phylogeny, venom composition and neutralization by antivenom in diverse species of Bothrops complex. PLoS Negl Trop Dis. 2013;7(9):e2442.

10. Cidade DA, Simão TA, Dávila AM, Wagner G, Junqueira-de-Azevedo IL, Ho PL, et al. Bothrops jararaca venom gland transcriptome: analysis of the gene expression pattern. Toxicon. 2006;48(4):437-61.

11. Durban J, Juárez P, Angulo Y, Lomonte B, Flores-Diaz M, Alape-Girón A et al. Profiling the venom gland transcriptomes of Costa Rican snakes by 454 pyrosequencing. BMC Genomics. 2011;12:259. doi:10.1186/ 1471-2164-12-259.

12. Morais-Zani K, Grego KF, Tanaka AS, Tanaka-Azevedo AM. Proteomic analysis of the ontogenetic variability in plasma composition of juvenile and adult Bothrops jararaca snakes. Int J Proteomics. 2013;2013:1-9.

13. Saad E, Barros LC, Biscola N, Pimenta DC, Barraviera SR, Barraviera B, et al. Intraspecific variation of biological activities in venoms from wild and captive Bothrops jararaca. J Toxicol Environ Health A. 2012;75(16-17):1081-90.

14. Camey KU, Velarde DT, Sanchez EF. Pharmacological characterization and neutralization of the venoms used in the production of Bothropic antivenom in Brazil. Toxicon. 2002:40(5):501-9.

15. Gutiérrez JM, León G, Lomonte B, Angulo Y. Antivenoms for snakebite envenomings. Inflamm Allergy Drug Targets. 2011;10(5):369-80.

16. Chippaux JP. Control of ophidism in Brazil: a model for Africa. J Venom Anim Toxins incl Trop Dis. 2010;16(2):188-90.

17. León G, Herrera M, Segura Á, Villalta M, Vargas M, Gutiérrez JM. Pathogenic mechanisms underlying adverse reactions induced by intravenous administration of snake antivenoms. Toxicon. 2013;15(76):63-76.

18. Silva IM, Tavares AM. Comparative evaluation of adverse effects in the use of powder trivalent antivenom and liquid antivenoms in Bothrops snake bites. Rev Soc Bras Med Trop. 2012;45(4):523-5.

19. Gutiérrez JM, Lomonte B, León G, Alape-Girón A, Flores-Díaz M, Sanz L, et al. Snake venomics and antivenomics: proteomic tools in the design and control of antivenoms for the treatment of snakebite envenoming. J Proteomics. 2009;72(2):165-82.

20. Gutiérrez JM, Lomonte B, León G, Rucavado A, Chaves F, Angulo Y. Trends in snakebite envenomation therapy: scientific, technological and public health considerations. Curr Pharm Des. 2007;13(28):2935-50.

21. Mors WB, Nascimento MC, Pereira BM, Pereira NA. Plant natural products active against snake bite: the molecular approach. Phytochemistry. 2000;55(6):627-42.

22. Teixeira VL. Produtos naturais marinhos. In: Pereira RC, Soares-Gomes A, editors. Biologia Marinha. 2nd ed. Rio de Janeiro: Interciência; 2002. p. 443-72.

23. Mayer AM, Rodríguez AD, Berlinck RG, Hamann MT. Marine pharmacology in 2005-6: marine compounds with anthelmintic, antibacterial, anticoagulant, antifungal, anti-inflammatory, antimalarial, antiprotozoal, antituberculosis, and antiviral activities; affecting the cardiovascular, immune and nervous systems, and other miscellaneous mechanisms of action. Biochim Biophys Acta. 2009;1790(5):283-308.

24. Cirne-Santos CC, Souza TM, Teixeira VL, Fontes CF, Rebello MA, Castello-Branco LR, et al. The dolabellane diterpene dolabelladienetriol is a typical noncompetitive inhibitor of HIV-1 reverse transcriptase enzyme. Antiviral Res. 2008;77(1):64-71.

25. Rocha FD, Soares AR, Houghton PJ, Pereira RC, Kaplan MA, Teixeira VL. Potential cytotoxic activity of some Brazilian seaweeds on human melanoma cells. Phytother Res. 2007;21(2):170-5.

26. Moura LA, Ortiz-Ramirez F, Cavalcanti DN, Ribeiro SM, Muricy G, Teixeira VL, et al. Evaluation of marine brown algae and sponges from Brazil as anticoagulant and antiplatelet products. Mar Drugs. 2011;9(8):1346-58.

27. Moura LA, Sanchez EF, Bianco EM, Pereira RC, Teixeira VL, Fuly AL. Antiophidian properties of a dolastane diterpene isolated from the marine brown alga Canistrocarpus cervicornis. Biomed Prev Nutr. 2011;1(1):61-6. 
28. Faioli CN, Domingos TF, de Oliveira EC, Sanchez EF, Ribeiro S, Muricy G, et al. Appraisal of antiophidic potential of marine sponges against Bothrops jararaca and Lachesis muta venom. Toxins (Basel). 2013;5(10):1799-813.

29. Teixeira VL. Produtos naturais marinhos. In: Pereira RC, Soares-Gomes A, editors. Biologia Marinha. 2nd ed. Rio de Janeiro: Interciência; 2009. p. 443-71.

30. Vasconcelos MA, Ferreira WJ, Pereira RC, Cavalcanti DN, Teixeira VL. Chemical constituents from the red alga Plocamium brasiliense (Greville) M. Howe and WR Taylor Biochem Syst Ecol. 2010;38:119-21.

31. Fonseca RR, Ortiz-Ramírez FA, Cavalcanti DN, Ramos CJB, Teixeira VL, Sousa-Filho APS. Allelopathic potential of extracts the from marine macroalga Plocamium brasiliense and their effects on pasture weed. Rev Bras Farmacogn. 2012;22(4):850-3

32. Ferreira WJ, Amaro R, Cavalcanti DN, Rezende CM, da Silva VA, Barbosa JE, et al. Anti-herpetic activities of chemical components from the Brazilian red alga Plocamium brasiliense. Nat Prod Commun. 2010;5(8):1167-70.

33. Gressler V, Fujii MT, Martins AP, Colepicolo P, Mancini-Filho J, Pinto E. Biochemical composition of two red seaweed species grown on the Brazilian coast. J Sci Food Agric. 2011;91(9):1687-92.

34. Claudino MM, Domingos TFS, Silva GA, Fonseca RR, Cavalcanti DN, Sanchez EF, et al. Inhibitory effect of the red seaweed Plocamium brasiliense against the toxic effects of Lachesis muta snake venom. J Appl Phycol. 2014;26(5):2047-54.

35. Fuly AL, de Miranda AL, Zingali RB, Guimarães JA. Purification and characterization of a phospholipase $A_{2}$ isoenzyme isolated from Lachesis muta snake venom. Biochem Pharmacol. 2002;63(9):1589-97.

36. Garcia ES, Guimarães JA, Prado JL. Purification and characterization of a sulfhydryl-dependent protease from Rhodnius prolixus midgut. Arch Biochem Biophys. 1978;188(2):315-22.

37. Kondo H, Kondo S, Ikezawa H, Murata R. Studies on the quantitative method for determination of hemorrhagic activity of Habu snake venom. Jpn J Med Sci Biol. 1960;13:43-52.

38. Nikai T, Mori N, Kishida M, Sugihara H, Tu AT. Isolation and biochemical characterization of hemorrhagic toxin from the venom of Crotalus atrox (western diamondback rattlesnake). Arch Biochem Biophys. 1984;231(2):309-19.

39. Yamakawa M, Nozaki M, Hokama Z. Fractionation of Sakishima habu (Trimeresurus elegans) venom and lethal hemorrhagic and edema forming activities of the fractions. In: Ohsaka A, Hayashi K, Sawai Y, editors. Animal, plant and microbial toxins: Biochemistry, vol. 1. New York: Plenum Press; 1976. p. 97-109.

40. Bochner R. The international view of envenoming in Brazil: myths and realities. J Venom Anim Toxins incl Trop Dis. 2013;19:38-51. doi:10.1186/ 1678-9199-19-29.

41. Machado C, Bochner R, Fiszon JT. Epidemiological profile of snakebites in Rio de Janeiro, Brazil, 2001-2006. J Venom Anim Toxins incl Trop Dis. 2012;18(2):217-24.

42. Soares AM, Ticli FK, Marcussi S, Lourenço MV, Januário AH, Sampaio SV, et al. Medicinal plants with inhibitory properties against snake venoms. Curr Med Chem. 2005;12(22):2625-41.

43. De Paula RC, Sanchez EF, Costa TR, Martins CHG, Pereira PS, Lourenço MV, et al. Antiophidian properties of plant extracts against Lachesis muta venom. J Venom Anim Toxins incl Trop Dis. 2010;16(2):311-23 [http://www.scielo.br/ scielo.php?script=sci_arttext\&pid=\$1678-91992010000200012]

44. de Oliveira EC, Anholeti MC, Domingos TF, Faioli CN, Sanchez EF, de Paiva SR, et al. Inhibitory effect of the plant Clusia fluminensis against biological activities of Bothrops jararaca snake venom. Nat Prod Commun. 2014;9(1):21-5

45. Domingos TFS, Ortiz-Ramírez FA, Villaça RC, Cavalcanti DN, Sanchez EF, Teixeira $\mathrm{VL}$, et al. Inhibitory effect of a Brazilian marine brown alga Spatoglossum schröederi on biological activities of Lachesis muta snake venom. Rev Bras Farmacogn. 2012;22(4):741-7.

46. Albuquerque $\mathrm{PL}$, Jacinto CN, Silva-Junior GB, Lima JB, Veras M d S, Daher EF. Acute kidney injury caused by Crotalus and Bothrops snake venom: a review of epidemiology, clinical manifestations and treatment. Rev Inst Med Trop Sao Paulo. 2013;55(5):295-301.

47. Barros LC, Soares AM, Costa FL, Rodrigues VM, Fuly AL, Giglio JR, et al. Biochemical and biological evaluation of gyroxin isolated from Crotalus durissus terrificus venom. J Venom Anim Toxins incl Trop Dis. 2011;17(1):23-33.

48. Oliveira AK, Paes Leme AF, Asega AF, Camargo AC, Fox JW, Serrano SM. New insights into the structural elements involved in the skin haemorrhage induced by snake venom metalloproteinases. Thromb Haemost. 2010;104(3):485-97.

49. Gutiérrez JM, Rucavado A. Snake venom metalloproteinases: their role in the pathogenesis of local tissue damage. Biochimie. 2000;82(9-10):841-50.

50. Gomes A, Das R, Sarkhel S, Mishra R, Mukherjee S, Bhattacharya S, et al. Herbs and herbal constituents active against snake bite. Indian J Exp Biol. 2010;48(9):865-78.

51. da Silva NM, Arruda EZ, Murakami YL, Moraes RA, El-Kik CZ, Tomaz MA, et al. Evaluation of three Brazilian antivenom ability to antagonize myonecrosis and hemorrhage induced by Bothrops snake venoms in a mouse model. Toxicon. 2007;50(2):196-205.

52. Fernandes CA, Comparetti EJ, Borges RJ, Huancahuire-Vega S, Ponce-Soto LA, Marangoni S, et al. Structural bases for a complete myotoxic mechanism: crystal structures of two non-catalytic phospholipases $A_{2}$-like from Bothrops brazili venom. Biochim Biophys Acta. 2013;1834(12):2772-81.

53. Fuly AL, Machado AL, Castro P, Abrahão A, Redner $P$, Lopes UG, et al. Lysophosphatidylcholine produced by the phospholipase $A_{2}$ isolated from Lachesis muta snake venom modulates natural killer activity as a protein kinase C effector. Toxicon. 2007;50(3):400-10.

54. Antunes TC, Yamashita KM, Barbaro KC, Saiki M, Santoro ML. Comparative analysis of newborn and adult Bothrops jararaca snake venoms. Toxicon. 2010;56(8):1443-58.

55. Asega AF, Oliveira AK, Menezes MC, Neves-Ferreira AG, Serrano SM. Interaction of Bothrops jararaca venom metalloproteinases with protein inhibitors. Toxicon. 2014;80(1):1-8.

\section{Submit your next manuscript to BioMed Central and take full advantage of:}

- Convenient online submission

- Thorough peer review

- No space constraints or color figure charges

- Immediate publication on acceptance

- Inclusion in PubMed, CAS, Scopus and Google Scholar

- Research which is freely available for redistribution 